\title{
TUTELA PROVISÓRIA ANTECEDENTE: EM BUSCA DA EFETIVIDADE DA PROTEÇÃO JURÍDICA DO MEIO AMBIENTE NO CONTEXTO DO ACORDO DE ESCAZÚ
}

\author{
Silas Silva Santos, Geovanna Carrijo dos Santos Dalefi Andrade \\ Universidade do Oeste Paulista - UNOESTE, Presidente Prudente, SP. E-mail: geo.carrijo@hotmail.com, \\ silas@unoeste.br
}

\section{RESUMO}

O presente trabalho busca compreender o instituto da tutela de urgência antecedente no contexto do Acordo de Escazú. Para isso, comentam-se os motivos que levaram à formação desse acordo e apresentamse alguns de seus artigos mais relevantes. Distinguem-se ainda os princípios da precaução e prevenção, os quais são vocacionados a protegerem o meio ambiente. 0 artigo também traz o conceito de tutela provisória de urgência e demonstra suas espécies. Aprofunda-se a análise da tutela provisória de urgência antecedente como instrumento destinado a garantir a efetividade jurisdicional na tutela do meio ambiente, chegando-se à conclusão de que aquele instituto se apresenta em sintonia com os compromissos assumidos pelo Brasil no âmbito do Acordo de Escazú. Para a concretização desta pesquisa e visando alcançar seus objetivos, aplicou-se o método hipotético dedutivo, produzindo-se uma pesquisa essencialmente exploratória. Para tanto, valeu-se de leitura e fichamento de livros, artigos científicos, revistas jurídicas, leis e jurisprudência.

Palavras-chaves: acordo de escazú; tutela de urgência antecedente; princípios ambientais.

\section{PROVISIONAL TUTELAGE ANTECEDENT: IN SEARCH OF THE EFFECTIVENESS OF THE LEGAL PROTECTION OF THE ENVIRONMENT IN THE CONTEXT OF THE ESCAZÚ AGREEMENT.}

\begin{abstract}
This paper seeks to understand the institute of preliminary injunctive relief in the context of the Escazú Agreement. To this end, it comments on the reasons that led to the formation of this agreement and presents some of its most relevant articles. The principles of precaution and prevention, which are intended to protect the environment, are also distinguished. The article also presents the concept of provisional emergency guardianship and demonstrates its species. It analyzes in greater detail antecedent provisional injunctive relief as a tool to ensure effective jurisdiction to protect the environment, concluding that such relief is in line with Brazil's commitments under the Escazú Agreement. In order to carry out this research and reach its objectives, the hypothetical deductive method was applied, producing an essentially exploratory research. To this end, it was based on the reading and analysis of books, scientific articles, legal magazines, laws and jurisprudence.
\end{abstract}

Keywords: escazú agreement; prior emergency guardianship; environmental principles.

\section{INTRODUÇÃO}

Vislumbra-se mundialmente uma crescente e arrazoada preocupação com o ambiente, uma vez que os estragos nele provocados não respeitam fronteiras geográficas e são sentidos por todos os seres vivos que nele habitam.

Desse modo, houve diversas conferências ambientais, entabulando, destarte, regras que servem de guia na elaboração dos 
ordenamentos jurídicos domésticos, no anseio de conquistar o equilíbrio ambiental.

Destaca-se, então, a Rio-92, a qual traçou diversos princípios que ressoaram ao longo daquela década e serviu de incentivo, por exemplo, na elaboração da Convenção Aarhus, firmado em fevereiro de 2005 na Dinamarca.

Tal convenção atuou como modelo do Acordo de Escazú, o qual possui também a finalidade de aplicar os direitos de acesso apregoados no princípio 10 da Rio-92.

Nesse sentido, busca-se entender os reflexos que os princípios do direito ambiental e as diretivas do Acordo de Escazú podem gerar no tratamento das tutelas provisórias antecedentes. Para tanto, é fundamental conhecer a tutela provisória de urgência e como está desenhada na legislação e, ainda, como podem ser utilizadas na defesa e amparo do meio ambiente.

A razão da pesquisa está apontada em verificar os meios que possam garantir a sustentabilidade do direito ambiental, para as gerações presentes e para aquelas que virão. Exibe-se, assim, os aspectos essências do Acordo de Escazú, elegendo e comentando alguns de seus artigos principais, bem como, trazendo as peculiaridades e distinções dos princípios da prevenção e precaução e o papel da ciência na aplicação desses. Ao fim, apresenta-se a importância da tutela de urgência antecedente na garantia de proteger e satisfazer o direito daquele que está a rogar por justiça ambiental.

\section{MÉTODOS}

$\mathrm{Na}$ perspectiva da natureza, a pesquisa ora projetada será aplicada, pois objetiva gerar conhecimentos para aplicações práticas dirigidas a solução de problemas específicos. No que concerne aos objetivos, a pesquisa é essencialmente exploratória. Do ponto de vista procedimental, trata-se de pesquisa bibliográfica, no âmbito da qual se promoveu a leitura de livros, artigos científicos, revistas jurídicas, leis e jurisprudência. Para a realização deste trabalho utilizou-se o método hipotético-dedutivo.

\section{DISCUSSÃO}

\section{Apontamentos do Acordo de Escazú}

O "planeta Terra está sitiado... pelo homem!" (BENJAMIN, 1995, p. 1), o qual conseguiu se adaptar e dominar a natureza de maneira agressiva e acelerada, como foi, v.g., na Revolução Industrial, que trouxe profundas transformações e, por consectário, impulsionou o desenvolvimento social (SALERT; FENSTERSEIFER, 2020).

Não houve, em princípio, uma preocupação em explorar o ambiente de forma equilibrada. Entretanto, essa situação, no decorrer dos anos, passou a ser repensada, na medida em que "A crise ecológica (ökologischen Krise) que vivenciamos hoje é resultado das "pegadas" deixadas pelo ser humano [...] responsável pelo esgotamento e degradação dos recursos naturais [...]" (SALERT; FENSTERSEIFER, 2020, p. 28).

Nessa razão, despertou-se, em âmbito global, a preocupação em criar medidas, tratados, a fim de proteger o ambiente, algo que ao longo das décadas foi se moldando e se consolidando, uma vez que "Todas as nações, simultaneamente atores e vítimas deste cerco, são atingidas pelo grande desafio da proteção ambiental à nossa e às futuras gerações." (BENJAMIN, 1995, p. 3).

Sarlet e Fensterseifer (2020) explicam o seguinte: aquele que está destruindo (ser humano), degradando o ambiente será, ao mesmo tempo, o responsável em "consertá-lo", ou seja, desenvolver medidas adequadas para sua proteção. Paradoxo esse que inflama o desejo de mudança.

Desse modo, sucederam-se alguns eventos mundiais, entre eles, a Conferência de Estocolmo de 1972, em que trouxe em seu bojo apontamentos a respeito do desequilíbrio ambiental, bem como a: "Conferência das Nações Unidas sobre Meio Ambiente e Desenvolvimento (1992); Cúpula Mundial sobre Desenvolvimento Sustentável - Rio+10 (2002); Conferência das Nações Unidas sobre Desenvolvimento Sustentável - Rio+20 (2012)." (OLIVEIRA, 2017, p. 21).

E foi a partir da Conferência da Rio+20, consubstanciado em aplicar o princípio 10 da Rio92, que o "Acordo Regional sobre Acesso à Informação, Participação Pública e Acesso à Justiça em Assuntos Ambientais na América Latina e no Caribe", ou resumidamente Acordo de Escazú, originou-se (MACHADO, 2019).

Em 04 de março de 2018, na cidade de Escazú- Costa Rica, o acordo foi firmado, após nove reuniões, o qual entrou em vigor no dia 22 de abril de 2021. O Brasil, embora o tenha assinado em 27 de setembro de 2018, ainda não o ratificou.

Esse é o primeiro tratado ambiental que engloba a América Latina e o Caribe, exibindo em 
seu íntimo conteúdos e problemáticas característicos dessa área.

Destarte, o referido acordo possui objetivo de:

garantir a implementação plena e efetiva, na América Latina e no Caribe, dos direitos de acesso à informação ambiental, participação pública nos processos de tomada de decisões ambientais e acesso à justiça em questões ambientais, bem como a criação e o fortalecimento das capacidades e cooperação, contribuindo para a proteção do direito de cada pessoa, das gerações presentes e futuras, a viver em um meio ambiente saudável e a um desenvolvimento sustentável (CEPAL, 2018, p. 14).

Martín (2019) informa que o objetivo esculpido no artigo 1 do Acordo de Escazú carrega em si o mesmo ideal que a Convenção de Aarhus, ou seja, o fortalecimento dos princípios de proteção ambiental e os reconhecimentos dos direitos subjetivos.

Machado (2019), por sua vez, expõe que tais preceitos do artigo em comento estão inseridos, de certa forma, nas leis e nas constituições dos países, como é vislumbrado no art. 225 da CF/88: é dever de os Estados prezar pela proteção ambiental. Porém, ressalta que “É preciso buscar-se o equilíbrio ecológico, para que o desenvolvimento não esteja só a serviço de um capitalismo duro e insensível, conseguindo-se, realmente, a sustentabilidade ambiental no desenvolvimento." (MACHADO, 2019, p. 20).

O Acordo de Escazú está alicerçado na tríade: acesso à informação, acesso à justiça e o direito de participação pública, os quais possuem uma relação de interdependência.

São, pois, preceitos que garantem uma presença efetiva e mais participativa da sociedade, possibilitando, dessa maneira, "[...] maior controle sobre as práticas poluidoras (ou potencialmente poluidoras) do ambiente perpetradas por agentes públicos e privados, inclusive tendo por premissa a concepção de uma cidadania ecológica." (SALERT; FENSTERSEIFER, 2020, p. 131).

Assim, torna-se essencial compreender em que está pautado o acesso à informação, uma vez que este amplia o conhecimento sobre os fatos que cercam o indivíduo e acabam servindo de "[...] componente essencial do exercício pleno da democracia participativa ecológica e, portanto, além de um dos pilares do princípio da participação pública, assume também a condição de direito fundamental" (SALERT; FENSTERSEIFER, 2020, p. 134).

É por essa razão que o Acordo de Escazú, em seu artigo 4, item 4, estatui que os Estados devem facilitar ao máximo o direito de acesso à informação sem precisar, entretanto, justificar os motivos para tal requisição, como está esculpido no artigo 5 , item 2 , "a" do pacto.

Leciona, dessa maneira, Machado (2019, p. 30) que: “[...] a Administração Pública Ambiental não tem razão para colocar sob prévia suspeita o cidadão ou a associação que procura saber da qualidade do ambiente".

É imperioso exibir que os Estados poderão ter o direito de acessar as informações que estejam sob poder de empresas privadas, para tanto deverão desenvolver mecanismo eficiente para obter êxito nessa empreitada.

Desse modo, Machado (2019) justifica que, talvez por meio de incentivos fiscais dos Estados, é possível imaginar que as empresas privadas venham a exibir suas informações ao público

Adverte, porém, o artigo 6, item 12 que o direito de acesso de informações pertencentes às empresas privadas alcança somente aquelas que podem causar algum risco a sociedade e/ou ambiente.

Nessa lógica, a doutrina comenta que "Se as informações ambientais produzidas nas empresas privadas permanecerem elas mesmas inacessíveis, impossível será aos poderes públicos e à sociedade civil fiscalizá-las" (MACHADO, 2019, p. 35). É por isso que a todo instante o acordo apresenta diversas técnicas e variadas formas para alcançar a efetividade da divulgação das informações.

O Acordo de Escazú inova também ao regulamentar no artigo 9 matérias de proteção aos defensores dos direitos humanos em matéria ambiental, algo "[...] sin precedentes en la región y en el mundo" (BALBín et al., 2019, p. 29). Caberá a cada Estado reconhecer as ameaças que 
circundam os defensores ambientais e buscar as soluções adequadas em cada caso.

Tem-se, por fim, que o Pacto de Escazú elege no artigo 3 alguns princípios do direito ambiental para servir de guia em sua implementação, com objetivo de erigir um meio mais igualitário, acessível e equilibrado.

\section{Princípio da prevenção e precaução}

A política ambiental esforça-se em garantir ou ao menos tenta garantir um menor impacto nele, uma vez que os estragos advindos dos danos ambientais são, em muitas ocasiões, irreversíveis ou de elevadíssimo custo de reparação.

Por essa razão, ganha-se espaço de destaque neste estudo os princípios da prevenção e da precaução. Muito embora possam, em um primeiro e desatento momento, ser entendido como expressões sinônimas, não o são, uma vez que são dotados de características e significados distintos.

Neste cenário, o princípio da prevenção torna-se um "[...] sustentáculo do direito ambiental, consubstanciando-se como seu objetivo fundamental." (FIORILLO, 2020, p. 106). Almeida (2015) expõe que a gênese deste instituto ocorreu na década de 1980 na denominada Convenção sobre Direito do Mar.

O princípio da prevenção vem afixado no dito popular de que é "melhor prevenir do que remediar" (SALERT; FENSTERSEIFER, 2020, p. 140), uma vez que a ciência comprova que certas condutas ocasionam prejudiciais consequências a saúde humana, fauna e flora. Nessa esteira, v.g., "[...] já se sabe que a retirada da mata ciliar provoca a perda da biodiversidade e o assoreamento dos rios, entre outras consequências". (SALERT; FENSTERSEIFER, 2020, p. 140).

Na ocasião do dano ambiental estar devidamente comprovado pela ciência, informa Fiorillo (2020) que, o Estado deve atuar de maneira incisiva em efetuar a justa punição àqueles que estão a utilizar de técnicas novas e danosas ao ambiente, servindo, destarte, de um "[...] estimulante negativo contra a prática de agressões ao meio ambiente" (FIORILLO, 2020, p. 107). Descreve ainda o referido autor que os Estados devem também recompensar, por intermédio de incentivos fiscais, aqueles que empregam métodos limpos em suas atividades.

Por sua vez e demandando uma análise mais acurada, chega-se ao princípio da precaução, surgindo na Alemanha na década de 1970, em que se "enunciou o Vorsorgeprinzip para guiar administradores no trato da poluição. No plano internacional, [...] ocorreu em 1987 em uma declaração adotada pela Conferência do Mar do Norte" (BELTRÃO, 2014, p. 19).

Foi, porém, em 1992, com a Declaração do Rio de Janeiro em Meio Ambiente e Desenvolvimento, sendo elaborado Princípio 15, que veio ganhar contorno e relevância na esfera mundial. Exibindo-se:

[...] proteger o meio
ambiente, os Estados
deverão aplicar
amplamente o critério de
precaução conforme suas
capacidades. Quando
houver perigo de dano
grave ou irreversível, a
falta de certeza científica
absoluta não deverá ser
utilizada como razão para
que seja adiada a adoção
de medidas eficazes em
função dos custos para
impedir a degradação
ambiental. (ONU, 1992,
não paginado).

Não há, pois, uma definição exata do que venha ser a precaução, motivo esse que enseja pontuais críticas.

Em linhas gerais, sua aplicação consiste numa probabilidade de dano ambiental, o qual, porém, a ciência, mesmo que implementando suas ferramentas e técnicas, não consegue comprovar veemente que determinado fato causará algum prejuízo grave e irreparável ao meio ou à saúde humana. Com isso, espera-se uma redobrada atenção e uma maior cautela ao aplicar uma nova tecnologia, um novo empreendimento, com o fito de que sejam preservados os interesses das presentes e futuras gerações (SALERT; FENSTERSEIFER, 2020).

Almeida (2015) defende ser de grande valia a aplicabilidade do princípio da precaução, uma vez que a ciência precisa empreender um aparato de estudo, equipe, testes entre outras fórmulas metodológicas que, por vezes, perdura por um lapso de tempo e, por consectário, não consegue ter o mesmo fôlego suficiente para alcançar o desenvolvimento célere da tecnologia. Nessa lógica, arremata a mesma autora que "[...] diante da dificuldade de se estabelecer certeza científica, impõe-se a aplicação da precaução 
quando houver risco significativo de dano ao meio ambiente ou à saúde" (ALMEIDA, 2015, p. 69).

Nessa dinâmica, jurisprudência demonstra que:

$\mathrm{O}$ direito fundamental ao meio ambiente ecologicamente equilibrado, insculpido no caput do art. 225 da Constituição da República, é interesse difuso, de titularidade

transindividual, emergindo, nesse cenário, os princípios da precaução e da prevenção, os quais impõem a priorização de medidas que previnam danos à vulnerável biota planetária, bem como a garantia contra perigos latentes, ainda não identificados pela ciência. (STJ- AgInt no TP 2476/ RJ, Relatora: Ministra Regina Helena Costa, Primeira Turma, Data de Julgameno: 01/09/2020, DJe:02/10/2020).

O princípio da precaução, desse modo, pode ser invocado, v.g., nos assuntos de ordem genética, como ocorre nos produtos que foram modificados geneticamente, campos eletromagnéticos, novos medicamentos e, ainda, a respeito do aquecimento global (MILARÉ, 2016).

Deve-se, contudo, haver ponderação ao aplica-lo, uma vez que não pode ser invocado por qualquer falácia ou por um medo imoderado de que venha causar algum risco (ALMEIDA, 2015). Assim, espera-se uma postura mais ativa e racional em avaliar os riscos no plano real, buscando sempre embasamentos científicos, ainda que este não demonstre com exatidão suas reais consequências ao meio ambiente (ANTUNES, 2015).

Antunes (2015, p. 31-32) que, em determinadas situações, tem-se aplicado a precaução de maneira desmedida. Em suas palavras:

O princípio da precaução
tem exercido
verdadeiro efeito
"manada"
sobre

diversas sociedades. Com isso quero dizer que basta alguém alegar que em determinada circunstância é necessário "precaução" para que todos passem a repetir o mote sem saber muito bem do que se está falando [...]. Grande parte da percepção do risco é, sem dúvida, devida à informação que possuímos sobre determinado tema, da nossa necessidade concreta de tomar esta ou aquela decisão e de um ambiente favorável ou desfavorável à medida pretendida ou sugerida. Advirta-se que, nem sempre, a percepção do risco corresponde ao risco real.

Busetti (2014) assevera ser importante jungir o princípio da proporcionalidade com a precaução. Ou seja, aquele servirá como ponto de equilíbrio, ante as incertezas científicas a fim de resguardar os direitos tutelados.

Cabe ressaltar também que, na dúvida sobre os riscos que determinado empreendimento pode causar, decidirá, então, a favor do meio ambiente, coadunando-se com o princípio in dubio pro natura. Argumenta, dessarte, a doutrina que este princípio é válido tanto aos perigos atuais quanto ao perigo futuro (CANOTILHO; LEITE, 2015).

Bem como, visualiza na jurisprudência, que recairá ao empreendedor o dever de demonstrar que a sua atividade não ensejará algum risco ao equilíbrio e a sustentabilidade ambiental. Desse modo, "Aquele que cria ou assume o risco de danos ambientais tem o dever de reparar os danos causados e, em tal contexto, transfere-se a ele todo o encargo de provar que sua conduta não foi lesiva". (STJ- REsp 1049822/RS, Relator: Ministro Francisco Falcão, Primeira Turma, Data de Julgamento: 23/04/2009, Dje: 18/05/2009).

Nesse sentido, o princípio da precaução está alinhado em adotar medidas a fim de resguardar de atividade que trazem potenciais riscos ao ambiente e a saúde humana, mesmo diante das incertezas da ciência. Pondera, com razão, Moraes (2011, p. 108, grifos do autor) que o instituto advém em virtude de uma sociedade 
de riscos, a qual "[...] não pode mais se utilizar de institutos e pilares clássicos do direito, tais como o da responsabilidade (a posteriori) do dano".

Portanto, torna-se fundamental recorrer ao ordenamento jurídico brasileiro e verificar quais dos procedimentos processuais são destinados a proteger, fazer cessar ou recompor os danos ambientais havidos.

\section{Comentários sobre a tutela provisória de urgência}

O Estado, ao retirar dos jurisdicionados a solução dos conflitos com as próprias forças, incumbiu-se de prestar a tutela jurisdicional, o qual deve concedê-la com observância das garantias constitucionais, ou noutras palavras, no denominado devido processo legal (ZAVASCKI, 2009).

Espera-se que o Estado empreenda, de modo efetivo e num tempo hábil, os meios necessários na prestação da tutela jurisdicional, com a finalidade de ser útil àquele que "bate às portas" do Judiciário, de modo que não se contenta, apenas, com o reconhecimento do direito.

Enverga, nesse sentido, Teori Albino Zavascki (2009, p. 66) ao afirmar que: “[...] não basta à prestação jurisdicional do Estado ser eficaz. Impõe-se seja também expedita, pois é inerente ao princípio da efetividade da jurisdição que o julgamento da demanda se dê em prazo razoável, "sem dilações indevidas"”. Perceba-se, então, que o Estado deve agir com eficiência na prestação da tutela jurisdicional e, ainda, estar atento às garantias constitucionais, a fim de promover a segurança jurídica.

Porém, há que se observar o fator tempo, sendo visto como um "maestro" em harmonizar a efetividade e a segurança jurídica, na medida que "O decurso do tempo [...] é inevitável para a garantia plena do direito à segurança jurídica, mas é, muitas vezes, incompatível com a efetividade da jurisdição, notadamente quando o risco de perecimento do direito reclama tutela urgente" (ZAVASCKI, 2009, p. 68).

Nesse diapasão, importa-se entender que a tutela provisória de urgência está alicerçada nos princípios da duração razoável do processo e do acesso à justiça (PIZZOL, 2020).

Observa-se, então, que os conteúdos estão alinhados do seguinte modo: disposições gerais (arts. 294 a 299, CPC), disposições gerais da tutela de urgência (arts. 300 a 302, CPC), procedimentos da tutela antecipada antecedente (arts. 303 e 304, CPC), procedimentos da tutela cautelar antecedente (arts. 305 a 310, CPC) e, por fim, há no art. 311 do CPC a tutela de evidência (BRASIL, 2015, não paginado).

A partir da leitura do art. 294, caput do CPC, vislumbra-se que a tutela provisória é o gênero, da qual são espécies a tutela de evidência e a tutela de urgência. Esta, por sua vez, divide-se, quanto ao momento, em antecipada e cautelar. Acresce ainda o parágrafo único do art. 294, CPC, que podem ser essas concedidas de maneira antecedente ou incidental (ALVIM, 2020). Atenta-se para o fato de que não há pagamento de custas do processo, art. 295 do CPC, na modalidade incidental (BRASIL, 2015, não paginado).

Cumpre ressaltar também que o magistrado deverá sempre justificar os motivos que o fazem conceder, modificar ou negar a tutela provisória, conforme o art. 298, CPC.

Zavascki (2009) esse dispositivo vem a repetir o que a Constituição Federal apregoa em seu art. 93, IX, e, por evidência, informa o referido autor, "[...] de que não se pode impor restrição a um direito constitucional fundamental sem prestar contas dos motivos que a justificaram" (ZAVASCKI, 2009, p. 79). Obtempera, porém, Alvim (2020) que os pedidos de tutela provisória, em razão da urgência, acontecem, por vezes, no início da causa e "Isso torna o trabalho do aplicador da lei uma atividade bastante delicada, e por esse motivo é indispensável que o juiz indique de modo claro e preciso as razões do seu convencimento" (ALVIM, 2020, p. 745).

A tutela provisória, então, visa atender às necessidades apresentadas diante do Poder Judiciário, para que seja possível garantir os direitos de modo efetivo e num tempo célere. Nesse sentido, Mitidiero (2019), valendo-se do nome de técnica antecipatória, explica que: A técnica antecipatória é
um meio para prestação
de tutela antecipada pelo
juiz do processo. A sua
exata formulação do
conceito de técnica
antecipatória depende da
conjugação dos critérios
estrutural, funcional e
cronológico. Do ponto de
vista estrutural, o
provimento antecipado é
formulado sob cognição 
sumária, é provisóriodestinado a durar enquanto não sobrevém o provimento definitivo-, e mantém uma relação de identidade, total ou parcial, com o provimento final. Não há uma relação de instrumentalidade entre tutela antecipada e tutela final- sequer mínima. O emprego da técnica antecipatória implica coincidênciaidentidade- e não instrumentalidade entre o provimento provisório e o provimento definitivo. Do ponto de vista funcional, visa a neutralizar os males do tempo no processo e distribuir isonomicamente o ônus temporal entre os litigantes mediante satisfação ou simples segurança da tutela do direito afirmado em juízo. Ela visa a neutralizar o perigo na tardança da tutela jurisdicional ou $a$ prestigiar a maior robustez da posição jurídica de uma das partes em comparação com a da outra. (MITIDIERO, 2019, p. 7374 , grifo do autor).

Fortalecendo, pois, as ideias exibidas acima e voltando o estudo para a tutela provisória de urgência, há que se identificar os requisitos essenciais para sua concessão. Esses, por seu turno, estão dispostos no art. 300, caput do CPC, quais sejam: a probabilidade do direito alegado pela parte e o perigo de dano ao resultado do processo.

Marinoni (2019) ensina que o perigo de dano ao resultado do processo deve ser demonstrado de maneira objetiva e direta, a fim de que seja capaz de convencer o juiz e, com isso, evitar a inutilidade da jurisdição.

Da mesma forma, em relação à probabilidade, o requerente deve demonstrar ao julgador que o seu pleito será, ao final do processo, outorgado (MARINONI, 2019). Com isso "A admissão de uma convicção de probabilidade como suficiente à concessão da tutela urgente decorre do perigo de dano, a impor solução e tutela jurisdicional imediatas". (MARINONI, 2019, p. 126).

Lembre-se de que para obtenção de uma tutela definitiva o magistrado utiliza de uma cognição exauriente (DIDIER JUNIOR; BRAGA; OLIVEIRA, 2018), ou seja, "O juiz, no processo de conhecimento, como regra geral, só decide com cognição exauriente, completa, plena. O juiz decide quando tem certeza de sua decisão" (WAMBIER, 2006, p. 32).

As tutelas pautadas na urgência, por seu turno, a cognição do juiz será superficial, sumária, em que sua decisão ocorrerá com base na probabilidade, haja vista que o fator tempo é crucial na garantia da jurisdição, não podendo, pois, o requerente esperar o desenrolar de toda marcha processual, na observância de um contraditório profundo (MARINONI, 2019).

Nessa dinâmica, tem-se que tutela antecipada visa adiantar o provimento que seria concedido ao final do processo de conhecimento, com o fito de garantir a eficácia em satisfazer o bem da vida desejado (DIDIER JUNIOR; BRAGA; OLIVEIRA, 2018).

Releva-se apontar que, na lógica do Código de Processo Civil, não será concedida a tutela provisória de natureza antecipada, conforme o art. 300, §3ㅇdo CPC, nas hipóteses dos efeitos serem irreversíveis.

A doutrina, todavia, vê com temperança o referido artigo. Arruda Alvim (2020), pautandose na ideia de proporcionalidade, defende ser admitido afastar essa regra, na busca de tornar efetiva a jurisdição. Para tanto, ressalta-se que o bem jurídico tutelado deve conter grande significância.

Partilhando desse pensamento, Wambier (2006, p. 37) acentua ser válida a outorga da medida, ainda que irreversível, uma vez que "[...] se deve sacrificar o direito eventual (não provado) da outra parte em função da necessidade de proteger um direito que aparenta ser bom, o do autor. Este é o princípio da proporcionalidade, a respeito do qual discorre boa doutrina".

Por seu turno, a tutela cautelar caracteriza-se pelo objetivo de proteger a futura eficácia, a frutuosidade da tutela satisfativa (MARINONI, 2019). De um outro modo, "[...] o direito à tutela de segurança serve para assegurar a realizabilidade futura de qualquer espécie de tutela do direito". (MITIDIERO, 2019, p. 72).

Em relação ao momento de concessão das espécies da tutela de urgência, verifica-se 
que podem ter caráter antecedente ou incidental. Este acontece na constância do processo, em que se fez o pedido definitivo, a fim de proteger a sua satisfação. $E$, no modo antecedente, o requerimento ocorre antes da tutela definitiva, objetivando antecipar sua efetividade (DIDIER JUNIOR; BRAGA; OLIVEIRA, 2018).

Fincadas essas premissas, passa-se, então, ao estudo da utilidade e adequação da tutela de urgência na defesa do direito ambiental.

Tutela de urgência: um instrumento para salvaguardar o meio ambiente

$O$ direito em ter um meio ambiente sustentável e hígido pertence a todos como descreve a Constituição Federal. Contentar-se apenas que seja imposto uma sanção de ressarcimento ao degradador após um dano no mundo fático, não é suficiente para a geração presente tampouco para futura.

Assevera, então, Viegas (2017) que no direito ambiental a tutela de urgência deve prevalecer como regra, a fim de atuar de modo preventivo, na garantia de um espaço saudável e equilibrado, haja vista que a recuperação ambiental é, em muitos casos, difícil, senão, improvável. Como vislumbra-se, por exemplo, a destruição de uma floresta, o rompimento de barragem e a extinção de uma espécie animal.

Dessa forma, tem se a necessidade de um "diálogo" entre as tutelas alistadas pelo direito material com as técnicas entabuladas pelo direito processual civil, objetivando a garantia da efetiva proteção ambiental. Explica Mitidiero (2019, p. 71, grifo do autor) que "existem tutelas que visam à outorga de proteção contra o ilícito e tutelas que visam à outorga de proteção contra o dano".

Informa, porém, Mirra (2017) que essas tutelas são concedidas, ordinariamente, após um longo processo de conhecimento e, por essa razão, o fator tempo pode ser prejudicial na garantia dos direitos ambientais. Nesse contexto, a tutela de urgência ganha sua importância.

Assim, a título de exemplo, a tutela inibitória visa evitar a ocorrência de ato contrário ao regramento, ou seja, um ilícito, tendo como papel de destaque proteger um direito que não seja patrimonial (MARINONI, 2008).

Pode ser ela invocada independentemente de um dano, encontrando, pois, seu alicerce no art. 5ㅇ, XXXV da CF. É, portanto, definida pela doutrina "[...] como uma tutela preventiva e específica. Preventiva porque voltada para o futuro; específica porque destinada a garantir o exercício integral do direito, segundo as modalidades originalmente fixadas pelo direito material". (MARINONI, 2008, p. 73).

Nesse caminho, Ursula Ribeiro de Almeida (2015), com aparente razão, disserta a respeito da importância de uma mudança do mindset jurídico. Ou seja, de querer buscar e, ainda, empreender meios que visam a prevenir o risco e/ou dano, não querendo, apenas, seu ressarcimento, principalmente na seara ambiental, que afeta de modo direito e indireto a vida humana. Dessa forma, a mesma autora alude que:

No âmbito do direito
ambiental, a tutela
inibitória é cabível contra
aquele que exerce
atividade de risco e não
adota as medidas
necessárias de prevenção
e precaução. Ainda que
não tenha ocorrido dano
ambiental, a violação do
dever de evitar ou
minimizar o risco ao meio
ambiente é suficiente para
a concessão da tutela
inibitória. (ALMEIDA,
2015, p. 111).

Com vista a sobrestar a continuidade do ilícito e/ou evitar eventual dano, pode-se afirmar que a tutela de urgência antecipada antecedente ganha seu destaque instrumental, pois é vocacionada a garantir a efetividade da jurisdição, na medida em que satisfaz de imediato a pretensão exibida em juízo.

Desse modo, narra o art. 303, caput, CPC, que essa técnica "[...] pode ser solicitada antes da propositura da ação mediante a qual a tutela final é postulada. A admissão [...] pressupõe uma situação de urgência incompatível com a demora inerente à elaboração da petição inicial da ação". (MARINONI, 2019, p. 220).

Por sua vez, a tutela cautelar, a cabo das exposições, busca garantir a eficácia da prestação jurisdicional. Então, após a ocorrência do dano "[...] a tutela do direito pode ser reparatória ou ressarcitória. A primeira visa a combater o dano na forma específica, ao passo 
que a segunda oferece à parte lesada o seu equivalente monetário". (MITIDIERO, 2019, p. 71).

A tutela cautelar antecedente tem por finalidade resguardar a prestação da tutela judicial, quando não possível a reparação do dano. Uma vez que, não é raro de imaginar, o degradador comece a se desfazer de seus bens, com o fito de obstaculizar eventual satisfação de uma condenação.

acórdão:

Nesse viés, cabe exibir o seguinte

\section{CONSTITUCIONAL,} ADMINISTRATIVO E AMBIENTAL. AÇÃO CIVIL PÚBLICA. DEGRADAÇÃO AMBIENTAL. ÁREA DE PRESERVAÇÃO

PERMANENTE. TUTELA CAUTELAR INIBITÓRIA (INDISPONIBILIDADE DE BENS). PRINCÍPIOS DA PREVENÇÃO E DA PRECAUÇÃO. II - Há de ver-se, ainda, que, em homenagem à tutela ambiental, ações agressoras do meio ambiente, como a noticiada nos autos de origem, devem ser rechaçadas e inibidas, com vistas na preservação ambiental, em referência. $\mathrm{Na}$ espécie dos autos, contudo, o desmatamento noticiado na peça de ingresso, que já ocorreu, e o consequente dano ambiental, que já se materializou, não afastam as medidas de cautela, necessárias, a fim de evitar-se o agravamento desse dano ambiental, sem descurar-se das medidas de total remoção do ilícito ambiental, na espécie, bem assim, da tutela de prevenção, para inibir outras práticas agressoras do meio ambiente, naquela área afetada. III - Assim, a medida constritiva postulada pelo Ministério Público Federal, além de adequada à finalidade a que se presta, afigura-se como sendo a única capaz de garantir a eficácia do provimento judicial postulado, sob pena de frustrar-se 0 seu resultado, em caso de procedência da demanda, ante a circunstância de que, com o ajuizamento da ação instaurada nos autos de origem e sem a concessão do pleito ali liminarmente formulado, o promovido disporá de tempo bastante para o desfazimento de seus bens. IV - Agravo de instrumento provido, para deferir a antecipação dos efeitos da tutela para determinar indisponibilidade de bens que estejam em nome do promovido, até o montante necessário à reparação do dano ambiental apontado pelo douto Ministério Público, com exceção dos valores eventualmente existentes em conta corrente, necessários,

comprovadamente, ao próprio sustento dos agravados e de sua respectiva família e à conservação de seu patrimônio. (TRF1-AG 00256182020164010000/ MG, Relator: Desembargador Federal Souza Prudente, Quinta Turma, Data de Julgamento 12/09/2018, Data de Publicação 01/10/2018).

Perceba-se, portanto, que a tutela cautelar não é vocacionada em garantir o direito, mas sim de assegura a sua eficácia processual. Desse modo, Código de Processo Civil alude, no art. 305, caput, que a petição inicial, no caráter antecedente, indicará as razões que embasam a lide, exibindo os fundamentos da probabilidade do direito e o perigo da demora. 


\section{CONCLUSÃO}

O estudo procurou demonstrar o impacto que o Acordo de Escazú pode trazer no tratamento da tutela provisória de urgência antecedente, como também pode-se verificar a utilização e os reflexos que os princípios do direito ambiental têm na garantia de um meio mais hígido e sustentável.

Apurou-se que o referido acordo possui conteúdo vasto e riquíssimo que apontam na defesa ambiental, estando, pois, atendo às dificuldades, às diversidades culturais e às problemáticas enfrentadas pela região em que foi elaborado. Nota-se, assim, sua importância e acréscimo à legislação pátria em firmar os direitos de acesso esculpidos na Rio-92, mesmo que o Brasil não tenha ratificado tal acordo.

Nesse sentido, o Pacto de Escazú estatui diferentes mecanismos para facilitar e efetivar o acesso à informação, no desejo de que todos os indivíduos tomem conhecimentos dos fatos que os circundam. Entre esses meios, cita-se, v.g., a possibilidade de acessar às informações das empresas privadas, bem como o dever dos Estados de garantir a divulgação dessas nos diferentes idiomas.

Conheceu-se também as diferenças e as peculiaridades que há entre os princípios da prevenção e da precaução, servindo, portando, a ciência de suporte na aplicação de cada.

Sugestionou-se, desse modo, ter cautela ao aplicar o princípio da precaução, uma vez que se vive numa sociedade de risco e que não se pode barrar seu desenvolvimento. Desse modo, decide-se até onde é válido o perigo. Com isso, o ônus probatório recairá ao empreendedor em exteriorizar que seu negócio não prejudicará o ambiente.

Vislumbrou-se, ainda, que os estragos na seara ambiental são, muitas das vezes, irreparáveis. É por isso, então, que se busca medidas e procedimentos adequados.

Dessa maneira, constatou-se que as tutelas provisórias são vocacionadas em garantir a efetividade processual. Nesse sentido, a tutela de urgência antecedente ganha sua relevância, pois visa à satisfação de início ao direito almejado como também à proteção de futura eficácia processual, sem a necessidade de todo trâmite processual, uma vez que o elemento tempo é crucial em salvaguardar o bem jurídico ambiental.

\section{REFERÊNCIAS}

ALMEIDA, Ursula Ribeiro de. Tutela de urgência no direito ambiental: instrumento de efetivação do princípio da precaução. São Paulo: Atlas, 2015.

ALVIM, Arruda. Manual de direito processual civil. 19. ed. São Paulo: RT, 2020.

ANTUNES, Paulo de Bessa. Manual de direito ambiental. 6. ed. São Paulo: Atlas, 2015.

BALBín, Aída Gamboa et al. La senda de sociedad civil hacia el Acuerdo de Escazú en América Latina y el Caribe. Lima: DAR, 2019. 91 p. Disponível em: https://www.dar.org.pe/archivos/publicacion/20 0_escazu_regional.pdf. Acesso em: 13 jan. 2021.

BELTRÃO, Antônio F.G. Curso de direito ambiental. 2. ed. São Paulo: Método, 2014.

BENJAMIN, Antonio Herman de Vasconcellos e. A proteção do meio ambiente nos países menos desenvolvidos: o caso da América Latina. São Paulo: Revista de Direito Ambiental, 1995. Disponível em: https://core.ac.uk/download/pdf/16019248.pdf. Acesso em: 13 jan. 2021.

BRASIL. Presidência da República Lei no 13.105, 16 de março de 2015. Código de Processo Civil. Brasília, $2015 . \quad$ Disponível em: http://www.planalto.gov.br/ccivil_03/_ato20152018/2015/lei/l13105.htm. Acesso em: 11 jun. 2021.

BRASIL. Superior Tribunal de Justiça. (1. Turma). Agravo Interno no Pedido de Tutela Provisória. Processual Civil. Agravo interno na tutela provisória. Código de Processo Civil de 2015. Aplicabilidade. Constitucional. Ambiental. Processual civil. Contracautela. Tutela provisória de urgência. Art. 300 do Código de Processo Civil. Requisitos. Presença. Direito ao meio ambiente ecologicamente equilibrado. Fumus boni juris. Interesse difuso. Princípios da prevenção e precaução. Inversão do ônus probatório. Súmula n. 618/STJ. Medida liminar concedida na origem. Revisão. Súmula n. 7/STJ. Periculum in mora em favor da proteção ambiental. Argumentos insuficientes para desconstituir a decisão atacada. Aplicação de multa. Art. 1.021, § 4으, do Código de Processo Civil de 2015. Descabimento. 
Agravo Interno no Pedido de Tutela Provisória no 2.476/RJ. Relatora: Ministra Regina Helena Costa. 01 set. 2020. Disponível em: https://scon.stj.jus.br/SCON/GetInteiroTeorDoAc ordao?num_registro $=201903638011 \& d t$ publica cao=02/10/2020. Acesso em: 07 jun. 2021.

BRASIL. Superior Tribunal de Justiça. (1. Turma). Recurso Especial. Ação Civil Pública. Dano ambiental. Agravo de instrumento. Prova pericial. inversão do ônus. Adiantamento pelo demandado. Descabimento. Precedentes. Recurso Especial no 1.049.822/RS. Relator: Ministro Francisco Falcão. 23 abr. 2009. Disponível em: https://scon.stj.jus.br/SCON/GetInteiroTeorDoAc ordao?num_registro $=200800840619 \& d t \_p u b l i c a$ cao=18/05/2009. Acesso em: 11 jun. 2021.

BRASIL. Tribunal Regional Federal da 10 Região. (5. Turma). Agravo de Instrumento. Constitucional, administrativo e ambiental. Ação civil pública. Degradação ambiental. Área de preservação permanente. Tutela cautelar inibitória (indisponibilidade de bens). Princípios da prevenção e da precaução. Agravo de Instrumento no 0025618-20.2016.4.01.0000/MG. Relator: Desembargador Federal Souza Prudente. 12 set. 2018. Disponível em: https://arquivo.trf1.jus.br/PesquisaMenuArquivo .asp?p1=00256182020164010000. Acesso em: 09 jul. 2021.

BUSETTI, Caroline. Dupla dimensão do princípio jurídico da precaução: princípio substantivo e instrumento de gerenciamento do risco ambiental. 2014. 124 f. Dissertação (Mestrado em Direito) - Universidade de Caxias Do Sul, Caxias do Sul, 2014. Disponível em: https://repositorio.ucs.br/handle/11338/782.

Acesso em: 05 jan. 2021.

CANOTILHO, José Joaquim Gomes; LEITE (organizadores). Direito constitucional ambiental brasileiro. 6. ed. São Paulo: Saraiva, 2015.

CEPAL. Comissão Econômica para a América Latina e o Caribe. Acordo regional sobre acesso à informação, participação pública e acesso à justiça em assuntos ambientais na América Latina e no Caribe 04 de março de 2018. Santiago: Nações Unidas, 2018. Disponível em: https://repositorio.cepal.org/bitstream/handle/1
1362/43611/S1800493_pt.pdf. Acesso em: 01 maio 2020.

DIDIER JUNIOR, Fredie; BRAGA, Paula Sarno; OLIVEIRA, Rafael Alexandria de. Curso de direito processual civil. 13. ed. Salvador: JusPodivm, 2018. v. 2

FIORILLO, Celso Antonio Pacheco. Curso de direito ambiental brasileiro. 20. ed. São Paulo: Saraiva, 2020.

MACHADO. Paulo Affonso Leme. Estudos de direito ambiental 3. São Paulo: Malheiros, 2019.

MARINONI, Luiz Guilherme. Antecipação da tutela. 10. ed. São Paulo: RT, 2008.

MARINONI, Luiz Guilherme. Tutela de urgência e tutela da evidência: soluções processuais diante do tempo da justiça. 3. ed. São Paulo: RT, 2019.

MARTín, Carmen Plaza. Proteção ao meio ambiente e participação pública: a evolução recente na Espanha e em âmbito internacional. Veredas do Direito, Belo Horizonte, v. 16, n. 35, p. 11-35, maio/ago., 2019. DOI https://doi.org/10.18623/rvd.v16i35.1543

MIRRA, Álvaro Luiz Valery. A tutela jurisdicional de urgência em matéria ambiental. Revista Consultor Jurídico, dez., 2017. Disponível em: https://www.conjur.com.br/2017-dez-

30/ambiente-juridico-tutela-jurisdicionalurgencia-materia-ambiental. Acesso em: $28 \mathrm{dez}$. 2020.

MILARÉ, Édis. Reação jurídica à danosidade ambiental: contribuição para o delineamento de um microssistema de responsabilidade. 2016. 362 f. Tese (Doutorado em Direito) - Pontifícia Universidade Católica de São Paulo, São Paulo, 2016. Disponível em: https://sapientia.pucsp.br/handle/handle/18874 \#preview-link0. Acesso em: 07 jun. 2021.

MITIDIERO, Daniel. Antecipação da tutela: da tutela cautelar à técnica antecipatória. 4. ed. São Paulo: RT, 2019.

MORAES, Gabriela Bueno de Almeida. O princípio da precaução no direito internacional. 2011. 211 f. Dissertação (Mestrado em Direito) - Faculdade de Direito da Universidade de São Paulo, São 
Paulo, 2011. Disponível em: https://teses.usp.br/teses/disponiveis/2/2135/td e-03092012-111415/pt-br.php. Acesso: 05 jan. 2021.

OLIVEIRA, Fabiano Melo Gonçalves de. Direito ambiental. 2. ed. Rio de Janeiro: Forense, 2017.

ONU. Organização das Nações Unidas. Declaração do Rio de Janeiro sobre Meio Ambiente e Desenvolvimento. Rio de Janeiro: ONU, $1992 . \quad$ Disponível em: https://www.defensoria.ms.def.br/images/nuded $\mathrm{h} /$ sistemas_onu/22_-

_Declara\%C3\%A7\%C3\%A3o_do_RJ_sobre_meio_ ambiente_e_desenvolvimento_-_1992_-_OK.pdf. Acesso em: 04 maio 2021.

PIZZOL, Patricia Miranda. Tutela coletiva: processo coletivo e técnicas de padronização das decisões. São Paulo: RT, 2020.

SARLET, Ingo Wolfgang; FENSTERSEIFER, Tiago. Curso de direito ambiental. Rio de Janeiro: Forense, 2020.

VIEGAS, Eduardo Coral. Princípio da prevenção no Direito Ambiental repercute no exame das tutelas provisórias. Revista Consultor Jurídico, fev., $2017 . \quad$ Disponível em: https://www.conjur.com.br/2017-fev-

11/ambiente-juridico-principio-prevencaoambiente-reflete-tutelas-provisorias. Acesso em: 28 dez. 2020.

WAMBIER, Luiz Rodrigues (coordenação). Curso avançado de processo civil. São Paulo: RT, 2006. v. 3.

ZAVASCKI, Teori Albino. Antecipação da tutela. 7. ed. São Paulo: Saraiva, 2009. 